\title{
Study of blast wave overpressures using the computational fluid dynamics
}

\section{Estudo das sobrepressões da onda de choque de uma explosão utilizando a fluidodinâmica computacional}
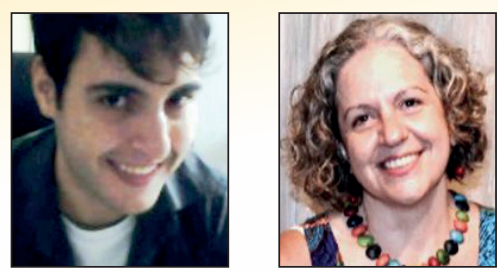

M. L. COSTA NETO a

eng_murilolimeira@hotmail.com

G. N. DOZ a

graci.doz@gmail.com

\begin{abstract}
The threats of bomb attacks by criminal organizations and accidental events involving chemical explosives are a danger to the people and buildings. Due the severity of these issues and the need of data required for a safety design, more research is required about explosions and shock waves. This paper presents an assessment of blast wave overpressures using computational fluid dynamics software. Analyses of phenomena as reflection of shock waves and channeling effects are done and a comparison between numerical results and analytical predictions has been executed, based on the simulation of several models. The results of this paper suggest that the common analytical predictions aren't accurate enough for an overpressure analysis in small stand-off distances and that poorly designed buildings may increase the shock wave overpressures due multiple blast wave reflections, increasing the destructive potential of the explosions.
\end{abstract}

Keywords: blasts, blasts waves, computacional fluid dynamics.

\section{Resumo}

Ameaças de ataques com bomba por parte de organizações criminosas e acidentes envolvendo explosivos químicos representam um perigo real às estruturas e a seus usuários. A gravidade destes problemas e a necessidade de informações que auxiliem a elaboração de projetos mais seguros demandam pesquisas relacionadas às explosões. Este trabalho faz uma avaliação das sobrepressões de ondas de choque oriundas da detonação de explosivos à base de TNT, utilizando a fluidodinâmica computacional. Pela simulação de diferentes modelos foi possível verificar fenômenos como reflexões de ondas de choque e efeitos de canalização e realizar a comparação dos resultados de sobrepressão de onda com predições analíticas. Os resultados indicam que as técnicas de predição são pouco acuradas na análise de estruturas muito próximas do ponto de detonação e que ambientes mal projetados podem favorecer o fenômeno das múltiplas reflexões de onda, aumentando o potencial destrutivo da explosão.

Palavras-chave: explosões, ondas de choque, fluidodinâmica computacional.

University of Brasilia, Department of Civil and Environmental Engineering, Brasilia, DF, Brazil 


\section{Introduction}

Shock waves and explosion phenomena, especially from high explosives, are useful for mining and for military applications. However, explosions might represent a severe risk for civilian structures and their users. A blast is a complex and nonlinear phenomenon that demand several analytical studies associated with numerical and experimental analysis. The main objective of these studies is the definition of fundamental controlling factors and blast parameters.

Recent researches about explosion receive important support from current computational resources. The blast experiments might be complex and expensive, for example, experiments based on elaborated urban environment or models involving high mass of explosives are uneconomical. The numerical development enable advanced structural modeling capabilities, facilitate the setup of large scale models and optimized building layouts.

The main objective of protective construction is to improve people and general contents survival probability after a blast event against a facility [1]. These constructions need sufficient ductility and redundancy to prevent progressive collapse [2]. Another important factor in a protective construction is the façade response to the blast loading that significantly affect the structure behavior [3].

A suitable internal layout of a protective building might facilitate the escape of hot gases from an internal explosion and prevent channeling effect due successive shock wave reflections. On the other hand, the global behavior of a given construction with adjacent buildings and the analysis of their structural geometries and construction materials may provide important information for designers to concept suitable strategies to mitigate damages from an explosion.

This paper presents a study of the explosions wherein numerical simulations based on computational fluid dynamics (CFD) were developed. The computational software Autodyn from Ansys $₫$ Workbench version 15 from 2014 [4] was used in this research. The simulated models are constituted by two close buildings under an external explosion. Several environment conditions as different level of openings, internal layouts and the presence of obstacles between the explosion and the buildings were considered in the analysis. A study of the channeling effect was conducted too.

The results for shock wave overpressure were compared with empirical predictions of several authors, for example, Kinney [5]. The

\section{Table 1}

Explosives and their TNT equivalency (9)

\begin{tabular}{|c|c|}
\hline Explosive & TNT Factor \\
\hline TNT & 1,00 \\
\hline Torpex & 1,20 \\
\hline PETN & 1,66 \\
\hline RDX & 1,60 \\
\hline HBX-3 & 1,02 \\
\hline Nitroglicerina & 1,50 \\
\hline Pólvora & 0,55 \\
\hline C4 & 1,18 \\
\hline
\end{tabular}

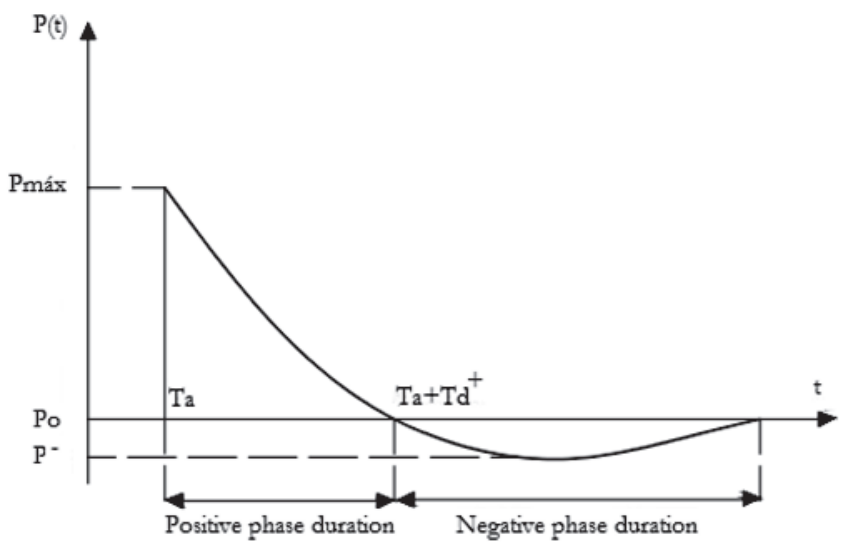

Figure 1

Blast wave pressure - time history

results enabled a comprehensive analysis of shock waves propagation in complex environment and their interaction with rigid surfaces. The shock wave reflections influence on the resulting overpressures was analyzed.

\section{The explosions and their basic parameters}

An explosion is summarily defined as rapid and sudden release of large amount of energy [6] wherein a violent expansion of the hot gases from the epicenter create a layer of compressed air, the shock wave [7]. Despite the high applicability on military operations, demolitions and mining, the explosions may represent a severe risk to the civilian structures and people when produced by accidents or criminal organizations. The explosions can be classified in nuclear, mechanical and chemical. The chemical explosions are related with high explosives (HE) that are a group of solid explosives able to produce shock waves when detonated in open air or underwater pressure pulses [8]. The properties and the effects of explosion of high explosives are more known than nuclear blast effects due the simplicity involved on the production and the utilization.

The type and quantity of explosive detonated are related with the magnitude of an explosion. An equivalence with TNT's energy may be used to evaluate the explosive power (Table 1) and that factor is largely utilized to determine proper masses of different kind of explosives in TNT. The parameters of a shock wave produced by an explosion can be suitable plotted in a graph, the pressure-time history (Figure 1). From the Figure 1:

Ta or Arrival time is the time when the shock wave reach the analysis point.

$\mathrm{Td}^{+}$or duration time of positive phase is the time between the arrival time ( $\mathrm{Ta}$ ) and the time when negative phase starts.

$\mathrm{Td}^{-}$or duration time of negative phase, starts when the positive phase of the shock wave ends and still be counted until the stabilization of ambient pressure.

$\mathrm{P}_{\text {máx }}$ or $\mathrm{P}$ or peak value of pressure is the highest value of pressure in positive phase of shock wave. $P_{\text {máx }}$ occur at the arrival time $(\mathrm{Ta})$. $\mathrm{P}^{-}$or under pressure is the lowest value of under pressure in the negative phase of shock wave. 
$\mathrm{P}_{\mathrm{o}}$ or ambient pressure is the reference standard pressure.

The overpressure $(\Delta \mathrm{P})$ is a pressure above standard atmospheric pressure. It can be measured by peak value of pressure $\left(P_{\text {max }}\right)$ minus atmospheric pressure $\left(P_{0}\right)$.

The scaled distance is a dimensional distance parameter used to estimate blast effects in a given distance of the explosion.

The scaled distance " $Z$ " (Equation 1) is defined by the relationship between the distance " $R$ " from an explosive charge with mass "W". The values of " $R$ " and "W" are measured in meters and kilograms, respectively.

$Z=\frac{R}{\sqrt[3]{W}}$

The explosive charge shape has a great influence in the definition of the shock front, this influence is very important in the analysis of close range explosions. Despite this, the use of spherical shaped explosives is common in the researches. In this case, the shock waves expand radially in the air from the detonation point. It is important to have previous knowledge about the shock wave behavior to evaluate the blast loading on a structure. To do so, there are important properties to consider in a shock wave analysis, such as the arrival time, the incident overpressure and the duration time of the positive phase.

Several researchers developed semi empirical formulations to estimate the overpressures of shock wave from a given distance to the detonation point. These formulations have low accuracy in some cases due the simplifications used in his development, but it still largely applicable in many problems.

Brode apud Mays and Smith [8] introduced the equations 2 and 3 to evaluate the overpressure $(\Delta \mathrm{P})$ in bar.

$\Delta P=\frac{6,7}{Z^{3}}+1 \quad($ bar $)$

$\Delta P=\frac{0,975}{Z}+\frac{1,455}{Z^{2}}+\frac{5,85}{Z^{3}}-0,019$

The equation 2 is applicable to evaluate overpressures in short distances wherein the overpressures is high ( $\Delta \mathrm{P}>10 \mathrm{bar})$. On the other hand, the equation 3 is applicable to medium and far distances wherein the overpressures are low $(0,1<\Delta \mathrm{P}<10$ bar $)$ Henrych apud Smith and Hetherington [7], based in experimental and numerical data, introduced the equations 4,5 and 6 to estimate shock wave overpressures in bar.

$$
\begin{aligned}
& \Delta P=\frac{14,072}{Z}+\frac{5,540}{Z^{2}}-\frac{0,357}{Z^{3}}+\frac{0,00625}{Z^{4}} \\
& \Delta P=\frac{6,194}{Z}-\frac{0,326}{Z^{2}}+\frac{2,132}{Z^{3}} \quad \text { (bar) } \\
& \Delta P=\frac{0,662}{Z}+\frac{4,05}{Z^{2}}+\frac{3,288}{Z^{3}} \quad \text { (bar) }
\end{aligned}
$$

The equation 4 is used to measure shock wave overpressure in close field $\left(0,05 \leq Z \leq 0,3 \mathrm{~m} / \mathrm{kg}^{1 / 3}\right)$. The equations 5 and 6 are applicable to $0,3 \leq Z \leq 1 \mathrm{~m} / \mathrm{kg}^{1 / 3}$ and $1 \leq Z \leq 10 \mathrm{~m} / \mathrm{kg}^{1 / 3}$, respectively. Newmark and Hansen apud Ngo et al. [6] introduced the Equation 7 to measure the shock wave overpressure in bar. That equation is similar to equations presented before, but is directly related with the charge mass $(\mathrm{W})$ and standoff distance $(\mathrm{R})$ instead of the scaled distance (Z).

$\Delta P=6784 \frac{W}{R^{3}}+93\left(\frac{W}{R^{3}}\right)^{1 / 2} \quad($ bar $)$

Kinney and Graham [5] introduced an equation to predict the shock wave overpressure in bar (Equation 8). Unlike the previous proposals, Equation 8 consider atmospheric pressure in the formula.

$\frac{\Delta P}{P o}=\frac{808\left[1+\left(\frac{z}{4,5}\right)^{2}\right]}{\sqrt[2]{1+\left(\frac{z}{0,048}\right)^{2}} \sqrt[2]{1+\left(\frac{z}{0,32}\right)^{2}} \sqrt[2]{1+\left(\frac{z}{1,35}\right)^{2}}}$

The Equation 9 was developed by Mills apud Ngo et al. [6]. This equation can be used to determine the overpressure of shock wave in $\mathrm{kPa}$.

$\Delta P=\frac{1772}{Z^{3}}-\frac{114}{Z^{2}}+\frac{108}{Z}$

The predictions of the shock wave overpressure of an explosion in the near field has lower accuracy than medium and far field due the high complexity involved in the formation of the shock wave and the expanding gases behavior in the first milliseconds of the explosion.

\section{Numerical analysis}

\subsection{Software}

On this paper the numerical simulations are developed in Autodyn, a hydrocode from Ansys $₫$ Workbench version 15 from 2014 [4].

The Autodyn is a hydrocode developed to analyze systems under intense or very fast loadings. This software is based in computational fluid dynamics that use explicit time integration to solve the equations of motion, this enable the modeling of problems involving impacts, explosions, fragmentation and several nonlinear dynamics problems.

The Autodyn allows modeling and simulating complex problems about explosions that could be uneconomical, unsafe or inviable to be done by blast experiments. The software enables the study of phenomena as channeling of the shock wave, Mach wave, measurement of the shock wave overpressure in complex environments, data related to negative phase and considerations about thermodynamics effects. Some of these phenomena weren't considered in semi empirical predictions presented earlier due their complexity. 


\subsection{Numerical simulations}

The primary goal of the simulations developed in this work is the analysis of the blast overpressures in various environments using the computational fluid dynamics. Three groups of simulations were developed.

In the first group, explosions in a free air were modeled using 1D models. The results for the shock wave overpressure were measured with gauges positioned in the model, henceforth this results were compared with the semi empirical predictions presented earlier in this work.

In the second group of simulations, the channeling effect was analyzed in 2D models. In these models, rigid obstacles were positioned to confine the explosion in order to canalize the energy. The analysis of the increment in the overpressure value due the multiple shock wave reflections has been executed, by positioning virtual gauges to measure them.

In the third group an urban environment has been modeled using 3D models. In that scenario, the overpressures of the shock wave from an explosion were studied. The models developed in these groups have some differences to enable the evaluation of different parameters, for example, the presence of obstacles between the explosion and the structures, positioning of the explosion and different internal layouts. The results for shock wave overpressure were collected by gauges and has been analyzed. Quadrilateral elements have been used to modeling the simulations of the first (1D) and second (2D) groups, and volume elements has been used to modeling the simulations of the third group (3D).

The models simulated share some similarities, for example, has been used Lagrangian mesh to model solids and Eulerian mesh to model fluids.

The Lagrangian meshes are meshes based in Lagrangian methods. In that case the modeled numerical mesh is enabled to move and distorts following the material motion.

The Eulerian mesh is a fixed mesh wherein the material flows through it. That mesh has a high computational cost to be processed due the large number of elements required to achieve accurate results [10]. The fluid-structure interaction can be achieved enabling the Euler-Lagrange coupling.

The remapping technique can be used to obtain computational time savings, as a good way to increase computational efficiency. This technique is based on a remap of the 1D analysis results in a 3D mesh.

The boundary conditions used in the borders of air model allows the representation of unlimited air medium. The buildings simulated in third group were modeled as rigid and were assumed as resting on a rigid ground. That assumptions enable an overall analysis of shock wave and a several gains of computational efficiency avoiding excessive deformations or fragmentation of the Lagrangian elements.

The Table 2 presents the properties of materials used in the simulations

\section{3 $1^{\circ}$ Group: The measurement of shock wave overpressures from an explosion of spherical TNT charge in free air - 1D}

The most simplified models to study blast waves consist in a detonation of spherical charge of TNT in free air in standard conditions.

This first group of simulations were developed to involve this simplified conditions enabling a suitable comparative analysis with semi empirical models. Several meshes sizes were used in these simulations.

The simulated models consist of a wedge formed by a combination of quadrangular elements filled with air (Figure 2). The charge of TNT was positioned in the center of model. The meshes sizes used were $5 \mathrm{~mm}, 10 \mathrm{~mm}, 20 \mathrm{~mm}$ and $50 \mathrm{~mm}$.

A $1 \mathrm{~kg}$ TNT charge was detonated and the pressures was being measured at standoff distances $2,0 \mathrm{~m}, 2,5 \mathrm{~m}, 2,9 \mathrm{~m}, 3,3 \mathrm{~m}, 3,7$ $\mathrm{m}, 4,0 \mathrm{~m}, 4,7 \mathrm{~m}, 5,0 \mathrm{~m}, 5,3 \mathrm{~m}, 5,9 \mathrm{~m}, 6,2 \mathrm{~m}, 6,7 \mathrm{~m}$ and 7,0 m. The air was considered in standard conditions.

\section{$3.42^{\circ}$ Group: The analysis of channeling effect - 2D}

The channeling effect occurs due complex environments geometries that can confine and canalize the energy of the explosion.

\section{Table 2}

Material properties

\begin{tabular}{|c|c|c|c|}
\cline { 2 - 4 } \multicolumn{1}{c|}{} & Ar & TNT & Concrete \\
\hline Equation of State & Ideal gas & Jones-Wilkins-Lee & Polinomial (Mie-Gruneisen) \\
\hline Specific heat & $717,6 \mathrm{j} / \mathrm{kgK}$ & - & - \\
\hline Reference density & $0,001225 \mathrm{~g} / \mathrm{cm}^{3}$ & $1,63 \mathrm{~g} / \mathrm{cm}^{3}$ & $2,50 \mathrm{~g} / \mathrm{cm}^{3}$ \\
\hline Reference temperature & $288,2 \mathrm{~K}$ & - & - \\
\hline Detonation velocity & - & $6,93.10^{3} \mathrm{~m} / \mathrm{s}$ & - \\
\hline Pressure & - & $2,1.107 \mathrm{kPa}$ & - \\
\hline Energy & - & $6,0.108 \mathrm{KJ} / \mathrm{m}^{3}$ & - \\
\hline Strength model & - & - & RHT concrete \\
\hline Failure model & - & - & RHT concrete \\
\hline
\end{tabular}




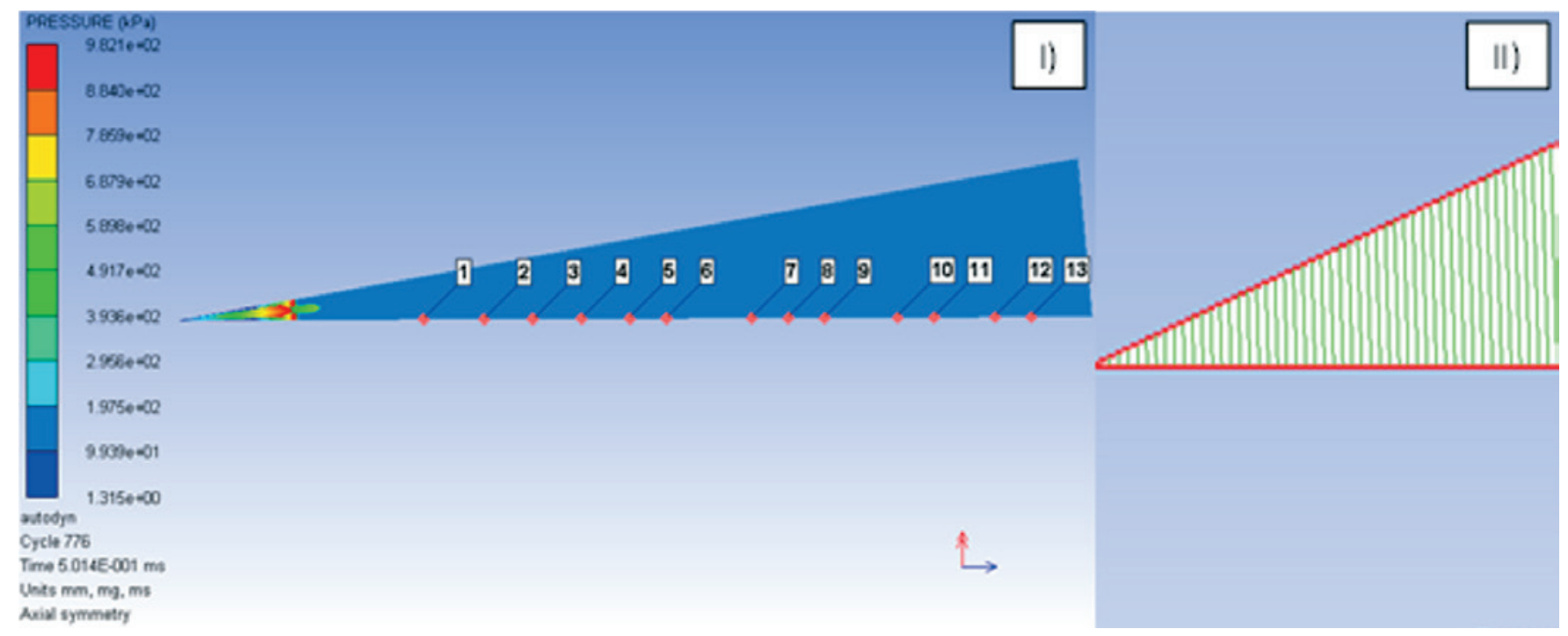

\section{Figure 2}

I) Shock wave propagating along the wedge element and gauges positioning; II) Mesh size detail

This effect may increase the shock wave overpressures.

In this group of simulations, four models were simulated (Figure 3) to allow a comprehensive analysis of the channeling effect influence in the shock wave overpressures value.

The 2D models simulated consist of a combination of quadrangular elements filled with air. Two rigid obstacles were positioned in this models in order to confine the explosion. A 50kg TNT charge was detonated (Figure 4) and the pressures were being measured by gauges 1,2 and 3 at standoff distances $2 \mathrm{~m}, 4 \mathrm{~m}$ and 8 $\mathrm{m}$, respectively.

In this models were used Eulerian mesh to model explosion environment and Lagrangian mesh to define the obstacles.

Large numerical models involving explosions may be modeled using mesh size of $500 \mathrm{~mm}$ in order to achieve a certain degree of

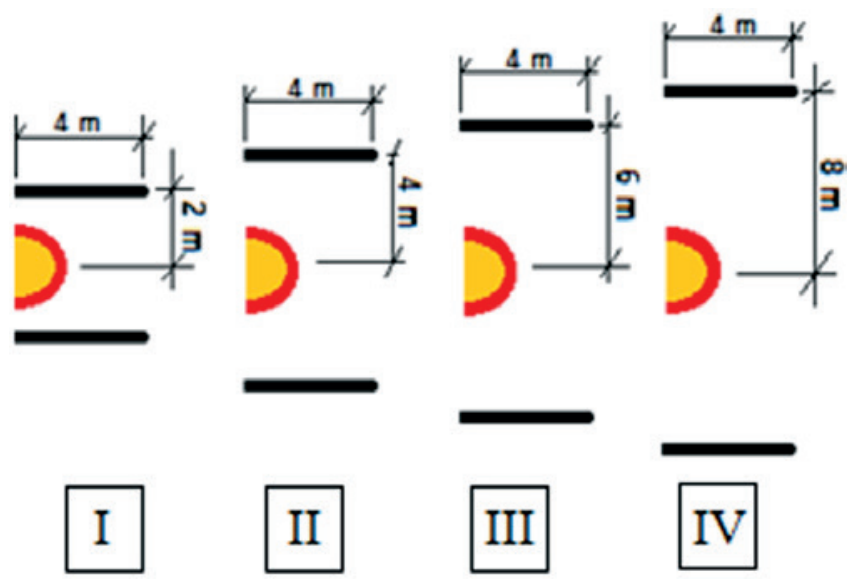

Figure 3

I) Obstacles at $2 \mathrm{~m}$ from explosion; II) Obstacles at $4 \mathrm{~m}$ from explosion; III) Obstacles at $6 \mathrm{~m}$ from explosion; IV) Obstacles at $8 \mathrm{~m}$ from explosion accuracy and a good computational efficiency [11]. However, in this case, a mesh size of $50 \mathrm{~mm}$ was used.

\section{$3.53^{\circ}$ Group: Measurement of blast wave overpressures in an urban environment- 3D}

The real scaled experiments involving explosions in an urban environment may be very complex or uneconomical. In this case, the

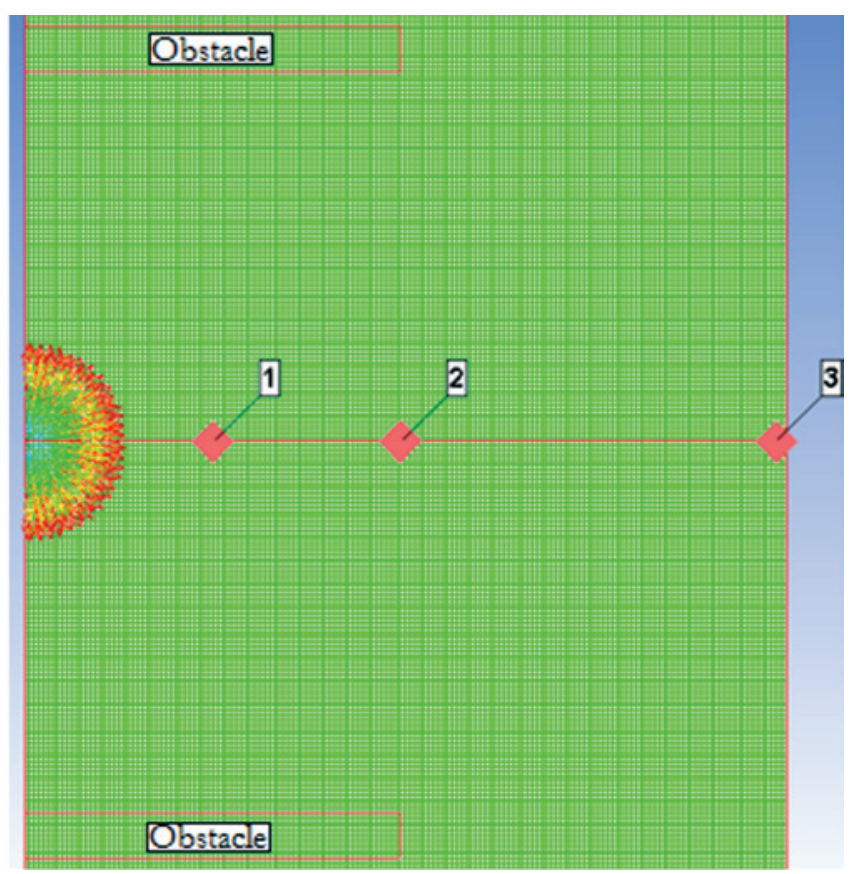

\section{Figure 4}

Mesh size of 50mm and gauges positioning along the model 

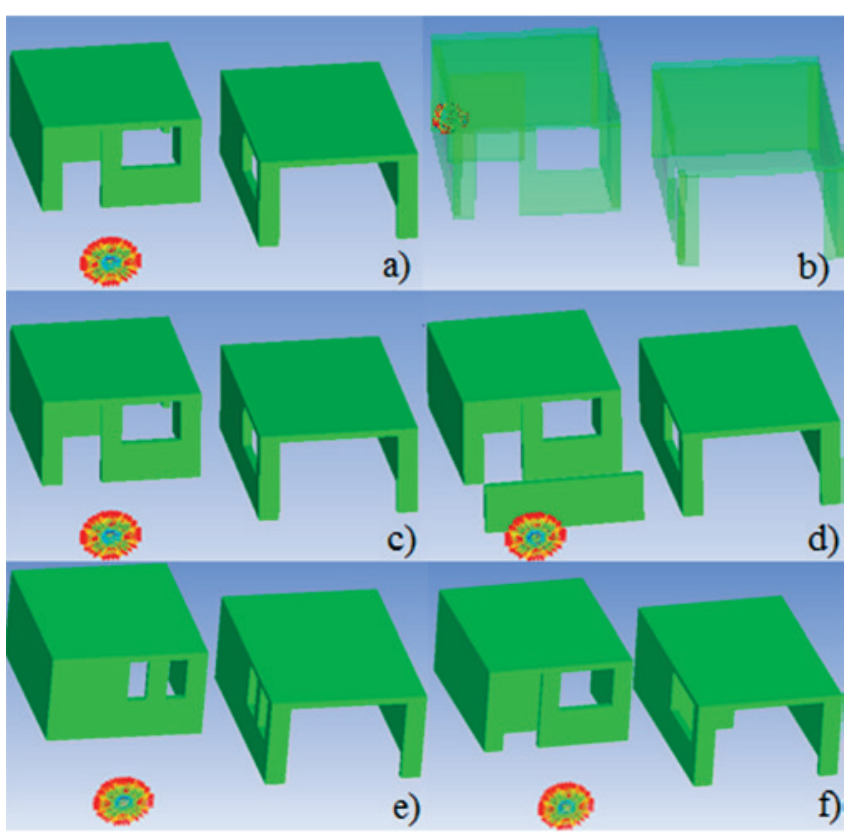

Figure 5

Simulated models a), b), c), d) and f)

numerical approach may be a good way to avoid operational problems and develop a reliable study.

The fundamental objective of this work is the analysis of the shock wave propagation and its interaction with rigid buildings. This enable the evaluation of overpressure history inside or outside the buildings.

Rigid concrete elements were used to model the edifications. This concept was utilized to develop six models, but a seventh model considering a free air blast was developed to allow a comprehensive comparative study.

Figure 5 shows the simulated models.
A $100 \mathrm{~kg}$ TNT charges has been detonated in all models except in the model C) wherein detonated a $10 \mathrm{~kg}$ TNT charge.

The models a) and b) have the same geometry and layout, but the positioning of the TNT charge is different.

The models a), c) and d) have many similarities, but in the model c) was used a $10 \mathrm{~kg}$ TNT charge. Another difference is the obstacle between the explosion and the buildings modeled in d) model.

The models e) and f) are identical with a) except the level of the openings of the buildings and the internal layout, respectively.

Figure 6 shows the positioning of the gauges at the $500 \mathrm{~mm}$ over the ground. The mesh size of the buildings and the rigid soil surface are shown, too.

Lagrangian elements were used to mesh the solids and the Eulerian mesh to model the fluids. The standard ambient conditions were used in the models.

The boundary conditions used in the models enables the structures and the soil to have rigid behavior. These assumptions allow an overall analysis of shock wave overpressures distribution and a gain of computational efficiency avoiding excessive deformations or fragmentation of the Lagrangian elements.

A mesh size of $500 \mathrm{~mm}$ may be used to simulate urban environments with good accuracy [11]. But in this work a mesh size of $50 \mathrm{~mm}$ was used.

\section{Results and discussion}

\subsection{Results from the $1^{\circ}$ Group (1D)}

The results obtained from the 1D models were compared with the results from empirical formulas presented earlier and were plotted in Figure 7.

The mesh sizes of $5 \mathrm{~mm}$ and $10 \mathrm{~mm}$ presented similar results with the Henrych and Brode predictions. The results for blast overpressures start an asymptotic convergence to large

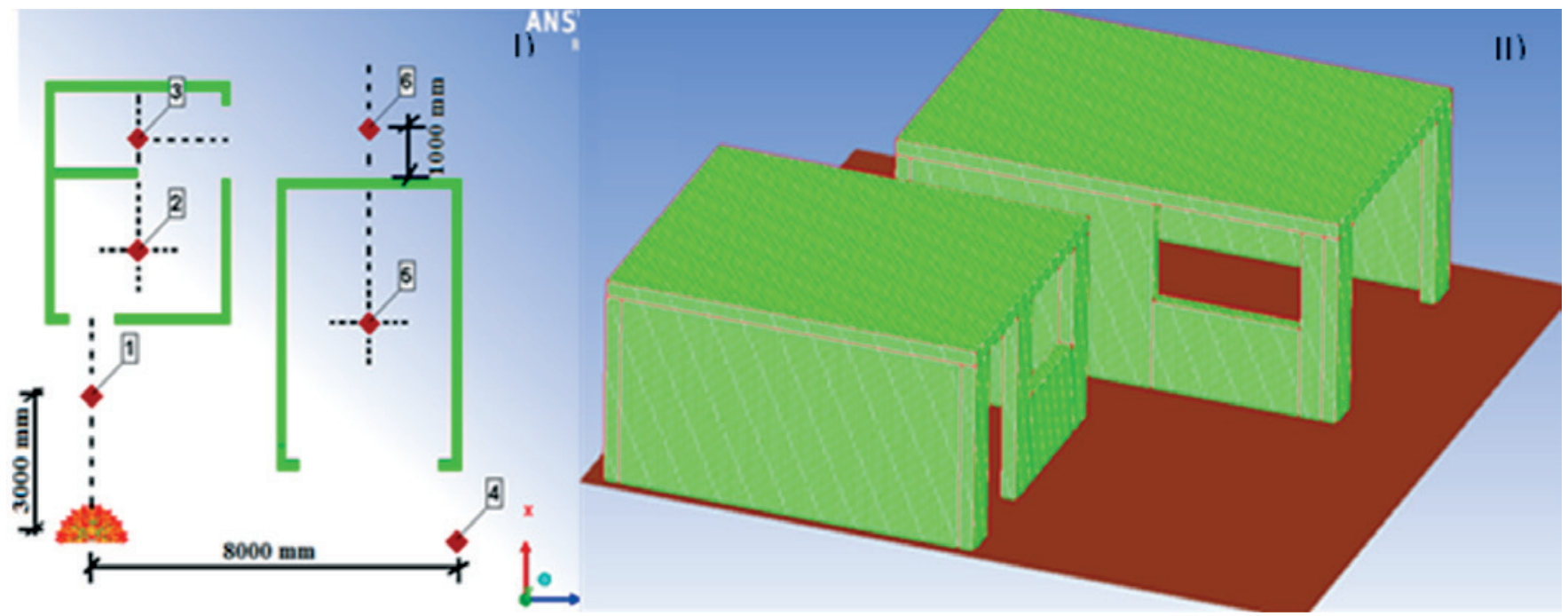

Figure 6

I) Gauges positioning; II) Mesh detail and rigid soil surface illustration 


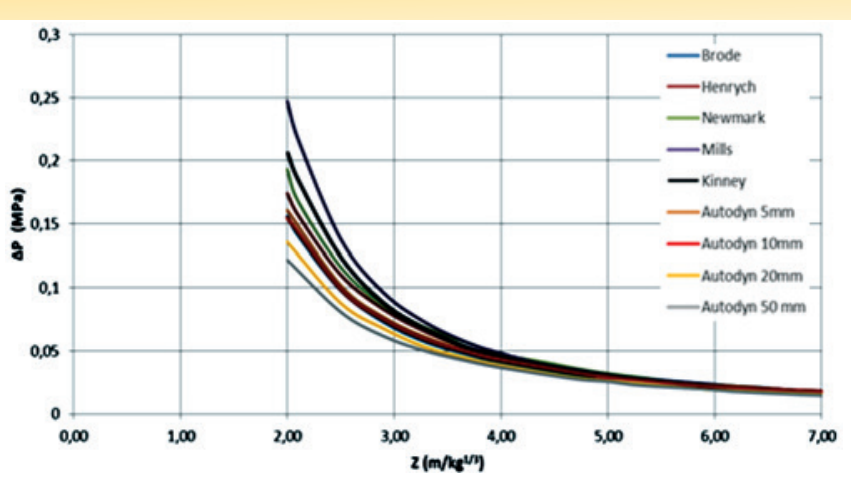

Figure 7

Comparison between the prediction methods and the numerical results of shock wave overpressures

scaled distances. On the other hand, results from short standoff distances $\left(Z<2 \mathrm{~m} / \mathrm{kg}^{1 / 3}\right)$ were less accurate.

The results obtained from the mesh sizes of $5 \mathrm{~mm}$ and $10 \mathrm{~mm}$ differ of $6 \%$. The convergence of these meshes starts at $2,5 \mathrm{~m} / \mathrm{kg}^{1 / 3}$.

\subsection{Results from $2^{\circ}$ Group (2D)}

Figure 8 presents the results obtained from this group of simulations.

\subsection{Results from $3^{\circ}$ group (3D)}

Table 3 shows the results of shock wave overpressure and arrival time from sensors 1, 2, 3, 4 and 5 for each simulation.

These results show that the presence of obstacle between the explosion and the buildings retained and dissipated an important parcel of blast wave energy. Consequently, it mitigated the incident overpressures in the buildings. However, in this case, the pressures measured by the gauge 4 were increased due the redirection of the blast energy. Therefore, the obstacles should be positioned wisely, they may redirect the explosion energy increasing the shock wave overpressure in the surroundings.

The case c) used the smallest TNT charge but the shock wave overpressure generated was high enough to severely damage the building [12].

The case b) an internal blast was simulated, and its results indicated a different behavior of shock wave overpressures distribution in the model. The location of the explosion in a confined environment increased the overpressures inside the building.

Considering an external explosion, a lower level of openings protected the internal environments of the buildings from blast wave overpressures. This result was expected.

The case f) presented slightly lower internal overpressures than case a) due the changes in internal layout

Table 4 presents a comparison between the simulations results
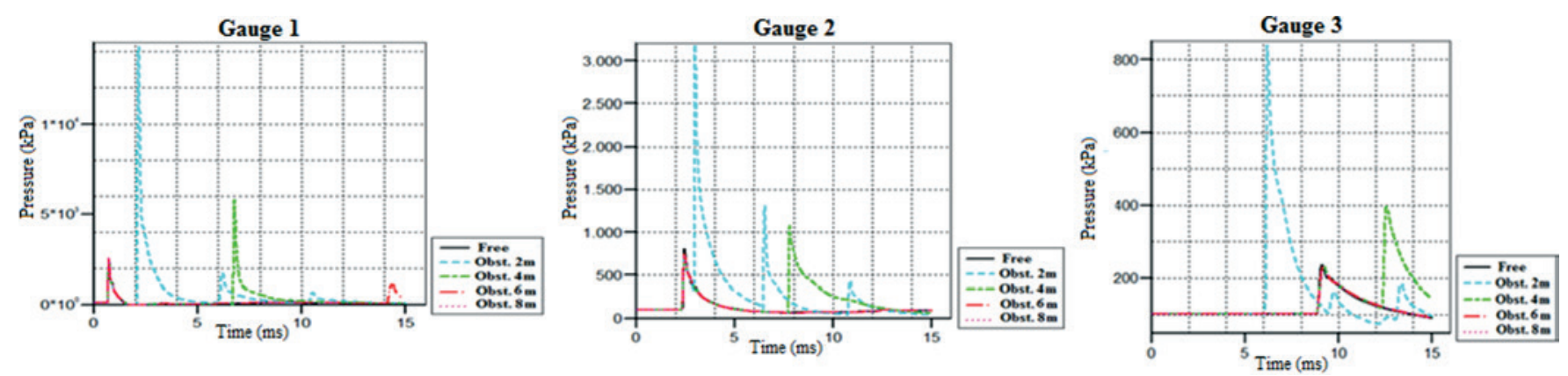

\section{Figure 8}

Blast wave pressure - time history from a $50 \mathrm{~kg}$ TNT charge

The successive peaks of shock wave overpressure are more frequently when the confinement is more accentuated. Therefore, a high level of confinement may increase the number of shock wave reflections.

The gauges 1 and 2 show the highest overpressures values due the channeling effect. That effect increased more than $300 \%$ the magnitude of the shock wave overpressure.

The case I presented the highest level of confinement. In that case, the shock wave reached the gauge 3 more fast than other cases. Thus, the channeling has an important influence in directing explosive energy.

The confinement area may be defined as the region between the obstacles. The Figure 9 shows the plot of the maximum overpressure vs confinement area.

This graph shows the relationship between the level of confinement and the increases of the overpressure value. The correct design of internal layouts of the structures can be useful to mitigate destructive effects from an explosion. Thus, the channeling effect of the shock wave must be analyzed and avoided during the design process of protective buildings, this is a dangerous phenomenon and cannot be neglected. and semi empirical predictions. An analysis of these results show that semi empirical predictions aren't accurate enough to evaluate shock wave overpressures in complex urban environments.

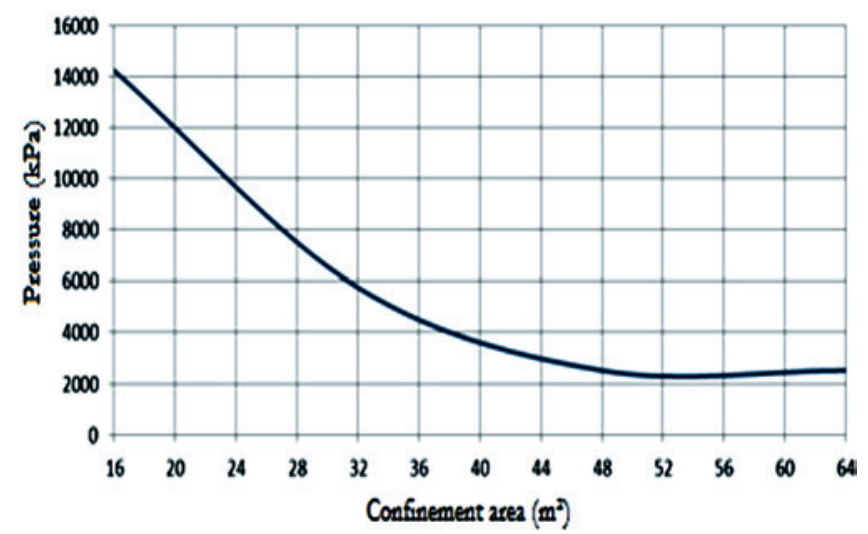

Figure 9

Blast wave overpressure vs confinement area 
Table 3

Results of the shock wave overpressures and the arrival time

\begin{tabular}{|c|c|c|c|c|c|c|}
\hline \multicolumn{2}{|c|}{ Simulation } & Gauge 1 & Gauge 2 & Gauge 3 & Gauge 4 & Gauge 5 \\
\hline $\begin{array}{c}\text { Free air blast } \\
\text { (without obstacles) }\end{array}$ & $\begin{array}{c}\Delta \mathrm{P}(\mathrm{kPa}) \\
\mathrm{Ta}(\mathrm{ms})\end{array}$ & $\begin{array}{l}2754 \\
0,99 \\
\end{array}$ & $\begin{array}{l}1226 \\
2,95 \\
\end{array}$ & $\begin{array}{l}543 \\
5,41\end{array}$ & $\begin{array}{l}636 \\
4,84 \\
\end{array}$ & $\begin{array}{l}717 \\
4,17\end{array}$ \\
\hline a) & $\begin{array}{c}\Delta \mathrm{P}(\mathrm{kPa}) \\
\mathrm{Ta}(\mathrm{ms})\end{array}$ & $\begin{array}{l}2754 \\
0,99\end{array}$ & $\begin{array}{l}425 \\
3,29\end{array}$ & $\begin{array}{c}340 \\
10,89\end{array}$ & $\begin{array}{l}684 \\
4,86\end{array}$ & $\begin{array}{l}336 \\
6,99\end{array}$ \\
\hline b) & $\begin{array}{c}\Delta \mathrm{P}(\mathrm{kPa}) \\
\mathrm{Ta}(\mathrm{ms})\end{array}$ & $\begin{array}{l}570 \\
4,83\end{array}$ & $\begin{array}{l}973 \\
4,19\end{array}$ & $\begin{array}{c}15731 \\
0,82\end{array}$ & $\begin{array}{l}- \\
-\end{array}$ & $\begin{array}{c}40 \\
9,36\end{array}$ \\
\hline c) & $\begin{array}{c}\Delta \mathrm{P}(\mathrm{kPa}) \\
\mathrm{Ta}(\mathrm{ms})\end{array}$ & $\begin{array}{l}1333 \\
1,51 \\
\end{array}$ & $\begin{array}{l}116 \\
6,00 \\
\end{array}$ & $\begin{array}{c}50 \\
12,31 \\
\end{array}$ & $\begin{array}{l}150 \\
9,02 \\
\end{array}$ & $\begin{array}{c}104 \\
10,96 \\
\end{array}$ \\
\hline d) & $\begin{array}{c}\Delta \mathrm{P}(\mathrm{kPa}) \\
\mathrm{Ta}(\mathrm{ms})\end{array}$ & $\begin{array}{l}224 \\
3,16\end{array}$ & $\begin{array}{c}121 \\
8,85 \\
\end{array}$ & $\begin{array}{c}65 \\
14,41 \\
\end{array}$ & $\begin{array}{l}1017 \\
4,31 \\
\end{array}$ & $\begin{array}{l}272 \\
6,47\end{array}$ \\
\hline e) & $\begin{array}{c}\Delta \mathrm{P}(\mathrm{kPa}) \\
\mathrm{Ta}(\mathrm{ms})\end{array}$ & - & $\begin{array}{c}72 \\
7,46 \\
\end{array}$ & $\begin{array}{l}162 \\
9,54 \\
\end{array}$ & - & $\begin{array}{l}250 \\
7,17 \\
\end{array}$ \\
\hline f) & $\begin{array}{c}\Delta \mathrm{P}(\mathrm{kPa}) \\
\mathrm{Ta}(\mathrm{ms})\end{array}$ & $\begin{array}{l}- \\
-\end{array}$ & $\begin{array}{l}130 \\
8,05\end{array}$ & $\begin{array}{l}363 \\
9,60\end{array}$ & $\begin{array}{l}- \\
-\end{array}$ & $\begin{array}{l}655 \\
6,90\end{array}$ \\
\hline
\end{tabular}

Table 4

Comparison between numerical results and semi empirical predictions

\begin{tabular}{|c|c|c|c|}
\hline Method $(\mathbf{k P a})$ & Gauge 1 & Gauge 2 & Gauge 4 \\
\hline Kinney e Graham & 2848 & 562 & 303 \\
\hline Newmark e Hansen & 3079 & 514 & 262 \\
\hline Mills & 8067 & 822 & 385 \\
\hline Free air (without obstacles) & 2754 & 1226 & 636 \\
\hline Case a) & 2754 & 425 & 684 \\
\hline
\end{tabular}

Semi empirical predictions may not consider important effects as ground reflection of Mach reflection.

\section{Conclusions}

In this work, the numerical simulations developed showed useful results to study the shock waves overpressures, an important damage mechanism of an explosion. That's why protective buildings designers require several information about it to create reliable projects. Therefore, the numerical approach of computational fluid dynamics emerges as a useful and efficiently tool to solve highly nonlinear problems involving explosives.

The first group of simulations (1D) showed similar results with the semi empirical predictions. In this case, in the numerical model was avoided shock wave reflections to achieve a good approach with the predictions. The meshes sizes of $5 \mathrm{~mm}$ and $10 \mathrm{~mm}$ presented similar results, and the convergence was observed in medium and far scaled distances.

The positioning of the explosive and the buildings geometry has a fundamental influence on the distribution of shock wave overpressures along the model. A high opening level of the façades promote the shock wave penetration into the rooms that result in increased overpressures inside the building. In this case, an opti- mized internal layouts design can be used to decrease the overpressure in internal environments.

The use of narrow corridors in the buildings may promote the occurrence of the channeling effect of the blast wave that increase the shock overpressures.

The channeling effect is a complex phenomenon that can be occur inside of the buildings or affect entire buildings in urban environments. Many cities have a complex distribution of their buildings, the proximity of tall buildings and the absence of open areas may difficult the dispersion of the blast energy, the shock waves can engulf entire buildings and reflect many times between nearby façades increasing their destructive effect.

A different distribution of the shock wave overpressures was observed during the internal explosions analysis. That results illustrates the high risk involved in the confinement of the explosion that can increase severely the overpressures value due the channeling effect. The right way to avoid or minimize this effect is the use of free spaces between the structures and suitable internal design avoiding narrow or dead end corridors.

Debris and fire may be a consequences of an explosion. But numerical analysis involving these aspects need to be executed separately due the high computational work demanded by this kind of simulation. The explosion may launch debris and fragments at 
high velocities dealing a considerable amount of damage to surrounding structural elements. Therefore, the design of protective structures need to be based in a deep analysis of fundamental damages mechanisms involved in an explosion event.

\section{Aknowledgements}

The authors gratefully acknowledge the financial support of the CNPq.

\section{References}

[1] KRAUTHAMMER, T. Modern Protective Structures, Taylor \& Francis Group, Florida, 2007.

[2] FU, F. Advanced Modelling Techniques in Structural Design, John Wiley \& Sons, West Sussex, 2015.

[3] PCl's Architectural Precast Concrete Services Committee. Blast Considerations, PCl designer's notebook, 2016.

[4] ANSYS® WORKBENCH. Version 15.0.7. Ansys, Inc, 2014.

[5] KINNEY, G. F., GRAHAM, K. J. Explosive Shocks in Air, Springer Science + Business Media, $2^{\text {nd }}$ ed, New York, 1985.

[6] NGO, T., MENDIS, P., GUPTA, A., RAMSAY, J. Blast Loading and Blast Effects on Structures, Electronic Journal of Structural Engineering, 76-91, 2007.

[7] SMITH, P. D., HETHERINGTON, J. G. Blast and Ballistic Loading of Structures, Butterworth-Heinemann, Oxford, 1994.

[8] MAYS, G. C., SMITH, P. D. Blast Effects on Buildings, Thomas Telford, London, 1995.

[9] USMANI, ZEESHAN-UL-HASSAN. Explosions Modeling - A Tutorial. Autumn Simulation Multi-Conference, The Society for Modeling \& Simulation International, 2012.

[10] BIRNBAUM, N. K., CLEGG, R. A., FAIRLIE, G. E. Analysis of Blast Loads on Buildings, Century Dynamics Incorporated, Oakland, California, 1996.

[11] LUCCIONI, B. M., AMBROSINI, D. Blast Load Assessment Using Hydrocodes, Mecánica Computacional, Vol. XXIV, Buenos Aires, 2005.

[12] APPLIED TECHNOLOGY COUNCIL (ATC), HINMAN, E., HINMAN CONSULTING ENGINEERS. Primer for Design of Commercial Buildings to Mitigate Terrorist Attacks, Federal Emergency Management Agency, United States, 2003. 